Journal of Current and Advance Medical Research

January 2018, Vol. 5, No. 1, pp. 29-32

http://www.banglajol.info/index.php/JCAMR

ISSN (Print) 2313-447X

ISSN (Online) 2413-323X

DOI: http://dx.doi.org/10.3329/jcamr.v5i1.36543

ORIGINAL ARTICLE open 2 Access

\title{
Foetal Outcome of among Women Presented with Fetal Head Engagement: Experience of 1440 Cases in Bangladesh
}

\author{
Dewan Shahida Banu ${ }^{1}$, Rifat Sultana ${ }^{2}$, Mahmuda Khatun ${ }^{3}$, Rowshan Hosne Jahan ${ }^{4}$, \\ Faiza Chowdhury ${ }^{5}$, Nasrin Sultana ${ }^{6}$, Shahana Nazneen ${ }^{7}$
}

\begin{abstract}
${ }^{1}$ Assistant Professor, Department of Gynaecology \& Obstetrics, Shaheed Taj Uddin Ahmad Medical College, Gajipur, Bangladesh; ${ }^{2}$ Assistant Professor, Department of Gynaecology \& Obstetrics, Shaheed Taj Uddin Ahmad Medical College, Gajipur, Bangladesh; ${ }^{3}$ Assistant Professor, Department of Gynaecology \& Obstetrics, Shaheed Taj Uddin Ahmad Medical College, Gajipur, Bangladesh; ${ }^{4}$ Senior Consultant, Maternity \& Child Health Training Institute, Azimpur, Dhaka, Bangladesh; ${ }^{5}$ Research Manager, NGO, Mirpur DOHS, Dhaka, Bangladesh; ${ }^{6}$ Assistant Professor, Department of Community Medicine, Shaheed Taj Uddin Ahmad Medical College, Gajipur, Bangladesh; ${ }^{7}$ Senior Consultant, Department of Gynaecology \& Obstetrics, Shaheed Taj Uddin Ahmad Medical College, Gajipur, Bangladesh
\end{abstract}

[Reviewed: 30 October 2017; Accepted on: 1 December 2017; Published on: 1 January 2018]

\section{Abstract}

Background: Foetal outcome is a great concern among the primigravida women presented with fetal head engagement. Objectives: The purpose of the present study was to see foetal outcome among the women presented with fetal head engagement. Methodology: This descriptive cohort study was carried out in the Department of Gynecology and Obstetrics at Sir Salimullah Medical College and Mitford Hospital, Dhaka from June 2006 to December 2006 for a period of sic (6) months. Primaigravida women with 38 or more weeks of pregnancy having single foetus with cephalic presentation were selected as study population. Foetal outcome was measured in terms of APGAR score. Result: A total number of 1440 pregnant women were recruited for this study. In this study the APGAR score of all the babies were good. APGAR score were low in 12 cases and returned to normal alter resuscitation. Out of 262 engaged cases 7 to 10 APGAR score was found in 261(99.6\%) cases. In 1178 unengaged cases 7 to 10 APGAR score was found in 1167(99.1\%) cases. APGAR score 4 to 6 was found in 1 case and 11 cases in engaged and unengaged group. However, 0 to 3 APGAR score was not reported in engaged and unengaged group. There was no statistical significant between the engaged and unengaged group considering the APGAR score of 7 to 10 and 4 to $6(\mathrm{p}=0.374)$. Conclusion: In conclusion fetal outcome is not significantly different between the engaged and unengaged pregnant women during considering the APGAR score. [Journal of Current and Advance Medical Research 2018;5(1):29-32]

Keywords: Foetal Outcome; APGAR score; engaged pregnant women; unengaged pregnant women; labour

Correspondence: Dr. Dewan Shahida Banu, Assistant Professor, Department of Gynaecology \& Obstetrics, Shaheed Taj Uddin Ahmad Medical College, Gajipur, Bangladesh; Email: fcshama@ hotmail.com; cell no.: +8801730038487

Cite this article as: Banu DS, Sultana R, Khatun M, Jahan RH, Chowdhury F, Sultana N, Nazneen S. Foetal Outcome of among Women Presented with Fetal Head Engagement: Experience of 1440 Cases in Bangladesh. J Curr Adv Med Res 2018;5(1):29-32 Funding: No funding agency.

Conflict of Interest: All the authors have declared that there was no conflict of interest.

Contributions to authors: Banu DS, Sultana R, Khatun M \& Jahan RH have contributed in protocol preparation upto surgical procedures \& the report writing; furthermore; Chowdhury F, Sultana N \& Nazneen S have written \& revised the manuscript.

Copyright: (O2018. Banu et al. Published by Journal of Current and Advance Medical Research. This article is published under the Creative Commons CC BY-NC License (https://creativecommons.org/licenses/by-nc/4.0/). This license permits use, distribution and reproduction in any medium, provided the original work is properly cited, and is not used for commercial purposes. 


\section{Introduction}

Lower rate of engagement of foetal head before labour is very important issue. It has been reported that the incidence of cephalo-pelvic disproportion is different in different age group ${ }^{1}$. Engagement of foetal head depends upon the size of the foetal head as well as the maternal pelvis; however, it is also influenced by pelvic inclination, race and ethnic group $^{2}$. It has been postulated that if the inclination of the pelvic inlet becomes greater with narrow sagital diameter of pelvic inlet, it delays in engagement of the foetal head ${ }^{3}$.

Traditionally it has been seen that engagement of fetal head is said to take place usually by 36 weeks of gestation and this should remain well engaged onwards ${ }^{4}$. Engagement has been defined as passage of biparietal diameter of fetal skull through the plane of the pelvic inlet. It has been also said that when the greatest horizontal plane the biparietal has passed the plane of the pelvic brim, the head is said to be engaged ${ }^{5}$. The sign of a high head at term in primigravidae is not a good sign and calls for investigation as to possible causes. Certainly many obstetricians take a pessimistic attitude towards eventual vaginal delivery, if the foetal head is not engaged at the onset of labour ${ }^{6}$.

On per vaginal examination lower pole of the unmolded head is usually at or below the level of the ischial spines ${ }^{4}$. The distance between the pelvic inlet and ischial spines is about $5 \mathrm{~cm}$. Lateral view radiography on standing position is confirmatory. In this situation the monitoring of fetal outcome is essential during delivery. The primigravida women are more vulnerable during delivery. It needs close and meticulous observation by examining the APGAR score among the fetus after delivery. In this context this present study was undertaken to see foetal outcome among the women presented with fetal head engagement.

\section{Methodology}

This descriptive cohort study was carried out in the Department of Gynecology and Obstetrics at Sir Salimullah Medical College and Mitford Hospital, Dhaka. This study was conducted from June 2006 to December 2006 for a period of sic (6) months. Sir Salimullah Medical College is a 500 bedded tertiary care teaching hospital situated in the heart of the old Dhaka city. This is one of the oldest hospitals in the Dhaka. Primaigravida women with 38 or more weeks of pregnancy having single foetus with cephalic presentation were selected as study population. Details history, clinical examination and relevant investigations were performed and were recorded in a predesigned data collection sheet. Proper engagement of the foetal head was assessed by the rule of 5 . When $2 / 5$ or less became palpable abdominally, it was labeled as engaged. All the patients were managed actively and were monitored by close and careful observation.

A partograph was filled and was recorded for each patient. Total duration of labour from beginning of phase was recorded. Foetal outcome was measured in terms of APGAR score at 5 minutes, incidence of resuscitation, incidence of admission in neonatal unit, incidence of intubation, ventilation and perinatal mortality. Birth weights were recorded immediately after delivery. Subsequently foetal head circumferences were measured and recorded. Data collected from each individual subject were compiled and analyzed using computer based software, the Statistical Package for Social Science (SPSS).

\section{Result}

A total number of 1440 pregnant women were recruited for this study. Highest incidence was found in the age group 21 to 24 yours. Maximum numbers of women were within the age group of 17 to 24 years which was $1258(87.4 \%)$ and the rest were belonging to the age group 25 to 32 years which was $182(12.6 \%)$ cases (Table 1 ).

\section{Table 1: Age Distribution among the Study} Population $(n=1440)$

\begin{tabular}{|l|c|c|}
\hline Age Group & Frequency & Percentage \\
\hline 17 to 24 Years & 1258 & 87.4 \\
\hline 25 to 32 Years & 182 & 12.6 \\
\hline Total & $\mathbf{1 4 4 0}$ & $\mathbf{1 0 0 . 0}$ \\
\hline
\end{tabular}

In this study the APGAR score of all the babies were good. APGAR score were low in 12 case and returned to normal alter resuscitation. Out of 262 engaged cases 7 to 10 APGAR score was found in 261(99.6\%) cases. In 1178 unengaged cases 7 to 10 APGAR score was found in $1167(99.1 \%)$ cases. APGAR score 4 to 6 was found in 1 case and 11 cases in engaged and unengaged group. However, 0 to 3 APGAR score was not reported in engaged and unengaged group. There was no statistical significant between the engaged and unengaged group considering the APGAR score of 7 to 10 and 4 to $6(\mathrm{p}=0.374)$ (Table 2$)$. 
Table 2: Distribution of Foetal Outcome among the Study Population $(n=1440)$

\begin{tabular}{|l|c|c|c|}
\hline $\begin{array}{l}\text { APGAR } \\
\text { Score }\end{array}$ & Engaged & Un-engaged & Total \\
\hline 7 to 10 & $261(99.6)$ & $1167(99.1)$ & $1428(99)$. \\
\hline 4 to 6 & $1(0.4)$ & $11(0.9)$ & $12(0.8)$ \\
\hline 0 to 3 & $0(0.0)$ & $00(0.0)$ & $00(0.0)$ \\
\hline Total & $\mathbf{2 6 2 ( 1 0 0 . 0 )}$ & $\mathbf{1 1 7 8}(\mathbf{1 0 0 . 0})$ & $\mathbf{1 4 4 0}(\mathbf{1 0 0 . 0})$ \\
\hline
\end{tabular}

The chi-square statistic was 0.7906 . The p-value was $>0.05$ (Not significant); Parenthesis within bracket indicates percentage

\section{Discussion}

The concept held by obstetrician and stated in standard text books is that foetal head engages in this maternal pelvis in the last four weeks of pregnancy $^{7}$. That does not happen one should suspect certain problems. Obstetricians generally feel that unengaged head in a primigravida at the onset of labour always calls for careful reevaluation of the whole cephalo-pelvic interrelationship ${ }^{8}$.

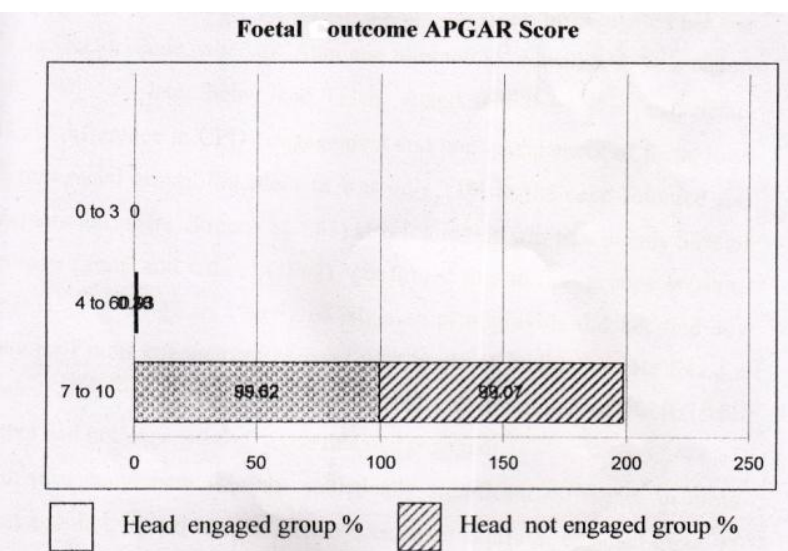

\section{Figure I: Showing the Faetal APGAR Score among the Engaed and non-engaed}

A total number of 1440 pregnant women were recruited for this study. Highest incidence was found in the age group 21 to 24 yours. Maximum numbers of women were within the age group of 17 to 24 years which was $1258(87.4 \%)$ and the rest were belonging to the age group 25 to 32 years which was $182(12.6 \%)$ cases. There was statistically significant difference in CPD, engagement and non engagement of foetal head is different racial group ${ }^{9}$. However Brigg ${ }^{7}$ in a study of Nigerian primigravida did not find any correlation of non-engagement of head with angle of inclination and found a significant difference between the mean head circumference of babies with heads that had not engaged and those that had engaged.

In this study the APGAR score of all the babies were good. APGAR score were low in 12 case and returned to normal alter resuscitation. Out of 262 engaged cases 7 to 10 APGAR score was found in 261(99.6\%) cases. In 1178 unengaged cases 7 to 10 APGAR score was found in $1167(99.1 \%)$ cases. APGAR score 4 to 6 was found in 1 case and 11 cases in engaged and unengaged group. However, 0 to 3 APGAR score was not reported in engaged and unengaged group. There was no statistical significant between the engaged and unengaged group considering the APGAR score of 7 to 10 and 4 to $6(\mathrm{p}=0.374)$. These results indicate that the fetal outcome is good in both engaged and non-engaged group. The diagnosis of disproportion, except the gross ones, can not be confidently made unless the patient is in labour and uterine action is adequate. It was observed that the duration of labour is significantly higher with non-engaged group as opposed to the engaged group. The finding is similar to the Endings of Jafarey.

There was no major fetal complication in these cases. The APGAR Score of all the babies were good except two in non-engaged group whose score returned to normal after resuscitation. There was no perinatal death in these study women. Although many obstetricians believe that nulliparous patients present mostly with engaged fetal heads in active labour ${ }^{10}$, this study and others indicate that most nulliparous patients present with an unengaged fetal head in active labour. This finding allows the clinician to be more optimistic regarding vaginal delivery of nulliparous patients who present with an unengaged vertex in active phase of labour and avoid hasty decisions toward cesarean delivery ${ }^{11}$. The results of this study have provided further evidence that abdominal palpation of the fetal head is an important component in the evaluation of women undergoing labour, since the prediction of successful vaginal delivery is more with abdominal criteria. Hence, in nulliparous patients a high station at the onset of labour is not necessarily an omnious finding even though the incidence of arrest disorders are higher when station is -3 or floating obstetricians can still be optimistic towards vaginal delivery ${ }^{12}$.

\section{Conclusion}

In conclusion fetal outcome is not significantly different between the engaged and unengaged pregnant women during considering the APGAR score. The findings of the study suggest that the 
obstetricians in Bangladesh should take a conservative attitude and non-engaged head at term in a primigravida. Women should not by itself be an indication for caesarean section.

\section{References}

1. Jafarey SN. Unengaged foetal head in Pakistani primigravida: frequency and outcome. Journal of Obstetrics and Gynaecology Research. 1988;14(1):13-6

2. Qureshi NS, Saleem F, Riaz S. Primigravida with non engaged foetal head at term: an audit of delivery outcome. Ann KE Med Coll 1999;5:177-9

3. Murphy K, Shah L, Cohen WR. Labour and delivery in nulliparous women who present with an unengaged foetal head. J Perinatol 1998;18(2):122-5

4. Debby A, Rotmensh S, Girtler O,Sadan O, Golan A, Glezerman M.Clinical significance of floating foetal head in nulliparous women in labour. J Reprod Med 2003;48:37-40 5. Roshan fekr D, Blakemore Kj, Lee j, Hueppchen NA, Witter FR. Station at onset of active labour in nulliparous patients and risk of cesarean delivery. Obstet Gynecol 1999;93:329-31
6. Daniel R, Blakemore KJ. Station at onset of active labour in nulliparous patients and risk of Caesarean delivery. Obstet Gynaecol 1999;93:329-31

7. Briggs ND. Engagement of the fetal head in the negro primigravida. BJOG: An International Journal of Obstetrics \& Gynaecology. 1981;88(11):1086-9

8. Chaudhary S, Farrukh R, Dar A, Humayun S. Outcome of labour in nullipara at term with unengaged vertex. J Ayub Med Coll Abbottabad 2009;21(3):131-4

9. Abbaspour Z, Sabzezary F, Afshari P. The Correlation between Engagement Time of Fetal Head in Early Active Phase and Delivery Outcome in Primigravida Women. Journal of Rafsanjan University of Medical Sciences 2005;4(4):326-241.

10. Dietz HP, Lanzarone V. Measuring engagement of the fetal head: validity and reproducibility of a new ultrasound technique. Ultrasound in Obstetrics \& Gynecology 2005;25(2):165-8.

11. Kushtagi P. Pattern of descent of foetal head in normal labour. Journal of the Indian Medical Association 1995;93(9):336-9

12. Barbera AF, Pombar X, Perugino G, Lezotte DC, Hobbins JC. A new method to assess fetal head descent in labor with transperineal ultrasound. Ultrasound in Obstetrics \& Gynecology 2009;33(3):313-9 